\title{
Inherited TP53 Mutations and the Li-Fraumeni Syndrome
}

\author{
Tanya Guha ${ }^{1}$ and David Malkin ${ }^{2}$ \\ ${ }^{1}$ Genetics and Genome Biology Program, The Hospital for Sick Children and Institute of Medical Science, \\ University of Toronto, Toronto, Ontario M5G 1X8, Canada \\ ${ }^{2}$ Division of Hematology/Oncology and Genetics and Genome Biology Program, The Hospital for Sick \\ Children; Departments of Pediatrics and Medical Biophysics, University of Toronto, Toronto, Ontario M5C \\ $1 \mathrm{X} 8$, Canada \\ Correspondence: david.malkin@sickkids.ca
}

$\mathrm{Li}$-Fraumeni syndrome (LFS) is a complex hereditary cancer predisposition disorder associated with early-onset cancers in diverse tissues of origin. Germline TP53 mutations are identified in $75 \%$ of patients with classic LFS. The lifetime likelihood of a TP53 mutation carrier developing cancer approaches $75 \%$ in males and almost $100 \%$ in females. Several genetic modifiers have been implicated to account for the phenotypic variability within and across LFS families; however, efforts to develop predictive algorithms of age of onset and type of cancers in individual patients have not yet found clinical use. Although it is not possible to prevent cancers from forming in LFS patients, novel protocols have been developed for surveillance for early tumor detection, leading to improvements in survival. Comprehensive studies of the genome and epigenome in LFS families in the context of germline TP53 mutations is anticipated to shed light on this intriguing, yet devastating, disease and to transform the clinical management of patients.

\section{CLINICAL DEFINITION OF THE LI-FRAUMENI SYNDROME}

i-Fraumeni syndrome (LFS) is a multiLcancer predisposition syndrome first reported in 1969 by $\mathrm{Li}$ and Fraumeni ( $\mathrm{Li}$ and Fraumeni 1969). In a retrospective epidemiological study examining medical charts and death certificates of 648 rhabdomyosarcoma (RMS) patients in the United States between 1960 and 1964, the investigators identified five families with an extensive family history of cancer (Li and Fraumeni 1969). Siblings and first- or second-degree relatives within the same parental lineage were noted to have developed sarcomas, whereas other first- and second-degree relatives had a history of other tumors, including breast cancer, leukemia, and carcinomas of lung, pancreas, and skin, at a much higher frequency than expected by chance. With the occurrence of such diverse cancer types at relatively young ages, the suggestion of a familial syndrome of multiple primary cancers arose. Prospective analysis of 24 other families together with further refinement of the tumor types characterized by the syndrome led, in 1989, to the "classic" definition of LFS (OMIM\#151623) as follows: a

Editors: Guillermina Lozano and Arnold J. Levine

Additional Perspectives on The p53 Protein available at www.perspectivesinmedicine.org

Copyright (C) 2017 Cold Spring Harbor Laboratory Press; all rights reserved; doi: 10.1101/cshperspect.a026187

Cite this article as Cold Spring Harb Perspect Med 2017;7:a026187 
proband with a sarcoma before the age of 45 years who has a first-degree relative with any cancer under the age of 45 years and another first- or second-degree relative with any cancer under the age of 45 years of age, or a sarcoma at any age (Li et al. 1988). The syndrome shows an autosomal dominant pattern of inheritance.

Based on the observations of many groups of the apparent phenotypic heterogeneity of the syndrome, further definitions have been proposed for families who show an extensive cancer history, but who do not conform to the classical definition. These are characterized as "Li-Fraumeni-like syndrome" (LFS-L) and arose following identification of the genetic basis of LFS in 1990. Birch et al. (1994) defined LFS-L as a proband with any childhood cancer, sarcoma, brain tumor, or adrenocortical carcinoma (ACC) under the age of 45 years, "and" a first- or second-degree relative in the same lineage with a typical LFS tumor at any age, "and" an additional first- or second-degree relative in the same lineage with any cancer before the age of 60 years. Eeles (1995) has defined LFS-L families to include first- or second-degree relatives with two different LFS component tumors (including bone- or soft-tissue sarcoma, breast cancer, brain tumor, leukemia, adrenocortical tumor, melanoma, and prostate cancer) at any age.

The "classic" definition of LFS further evolved by Chompret and colleagues includes recurrent phenotypes found in a prospective analysis of 2691 children with a solid tumor history before the age of 18 . The revised criteria are a proband with a characteristic LFS component tumor (sarcoma, brain tumor, breast cancer, ACC) before 36 years of age; and at least one first- or second-degree relative affected by one LFS component tumor mentioned above before the age of 46 years or by multiple tumors; "or" a proband with multiple primary tumors, two of which belong to the LFS component spectrum tumors, the first of which occurred before 46 years (except for breast cancer, if the proband has a breast cancer); "or" a proband with ACC, regardless of age of diagnosis or family history (Chompret et al. 2001). Based on further gen- otyping studies, Tinat et al. (2009) further revised the Chompret criteria, most notably by increasing the age of cancer onset and including pediatric cancers for which genetic testing should be undertaken, regardless of family history. These criteria are now generally used to guide gene mutation testing: a proband with a characteristic LFS component tumor (soft tissue sarcoma, osteosarcoma, brain tumor, breast cancer, ACC) before 46 years of age "and" at least one first- or second-degree relative with an LFS tumor (except breast cancer, if proband has breast cancer) before age of 56 years, or with multiple tumors "or" a proband with multiple primary tumors (except breast tumors), two of which belong to the LFS component spectrum tumors, the first of which occurred before 46 years "or" a patient with ACC or choroid plexus carincoma (CPC), irrespective of family history. More recently, several other cancers have been added to the list of those for whom gene testing is highly suggested, including anaplastic rhabdomyosarcoma (mutant gene carrier rate of 75\%) (Hettmer et al. 2014), hypodiploid acute lymphoblastic leukemia (ALL) (carrier rate $\sim 50 \%$ ) (Walsh et al. 2012; Comeaux and Mullighan 2016), and very earlyonset breast cancer $(<30$ years of age) in whom the gene carrier rate may be as high as $10 \%$, approaching similar rates as for BRCA1/2 (McCuaig et al. 2012).

\section{MOLECULAR PATHOGENESIS OF LFS}

It was not until 20 years after the first description of LFS, when Malkin and colleagues discovered the molecular etiology of the disease in 1990 (Malkin et al. 1990). Based on previous observations of somatic TP53 inactivation in sporadic forms of most cancers associated with the LFS spectrum, a candidate gene approach was used to identify germline heterozygous TP53 point mutations in five classic LFS families. Sequencing revealed germline missense mutations in the p53 DNA-binding domain in all families. Numerous subsequent studies confirmed these initial findings, but have also shown that germline mutations are distributed across the TP53 gene (including rare intronic 
Inherited TP53 Mutations and Li-Fraumeni Syndrome

mutations) in a pattern that essentially overlaps that of the spectrum of somatic mutations (p53.iarc.fr). More than 500 families are reported in the literature; however, it is believed that thousands, if not tens of thousands, of families harbor TP53 mutations but are generally not recognized. Recent attention to the relevance of genetics as the underlying basis of many human cancers is transforming the ways that clinicians document family histories, and more attention is leading to a rapid increase in numbers of families referred for genetic testing worldwide.

Missense mutations account for $74 \%$ of germline TP53 mutations, followed by nonsense mutations $(\sim 9 \%)$, and splice mutations $(\sim 8 \%)$. The majority of mutations occur in the highly conserved DNA-binding domain and the six most common "hotspot" mutations are found in codons 175, 245, 248 (two common substitutions), 273, and 282 (p53.iarc.fr). Only $60 \%$ to $80 \%$ of "classic" LFS families, 40\% of LFS-L families, and 30\% individuals meeting the revised Chompret criteria harbor germline TP53 mutations (Mai et al. 2012). The frequency of de novo mutations in LFS patients is not well characterized, although estimates range between $7 \%$ and 20\% (Chompret et al. 2000; Gonzalez et al. 2009).

\section{LFS TUMOR SPECTRUM, GENDER DISTRIBUTION, AND AGE OF ONSET}

As can be inferred from the clinical definitions noted above, LFS predisposes individuals to a wide range of cancer types, unlike most other dominant cancer predisposition syndromes that tend to be organ specific (or at most three to four organs). Although $>50 \%$ of sporadic cancers are known to harbor somatic TP53 mutations, those tumor types are relatively underrepresented in the LFS phenotype. For example, $43.28 \%$ of colon cancers harbor somatic TP53 mutations, but only $2.8 \%$ of germline TP53 carriers develop colorectal cancer ( $\mathrm{p} 53$. iarc.fr). Nonetheless, when these tumors do occur in the context of LFS, they do so at a strikingly lower age of onset than their sporadic counterparts (Nichols et al. 2001).

Despite the intrafamilial and interfamilial heterogeneous clinical presentation of tumors in LFS, five "core" cancers are most commonly observed: breast cancer, soft tissue sarcoma, brain tumors, ACC, and bone sarcomas (Fig. 1) (Li and Fraumeni 1969; Lynch et al. 1978; Li et al. 1988). Less frequent tumor sites include lung, colon, hematological, skin, stomach, and ovary (Nichols et al. 2001).

With respect to gender distribution of cancers in affected LFS patients, a retrospective

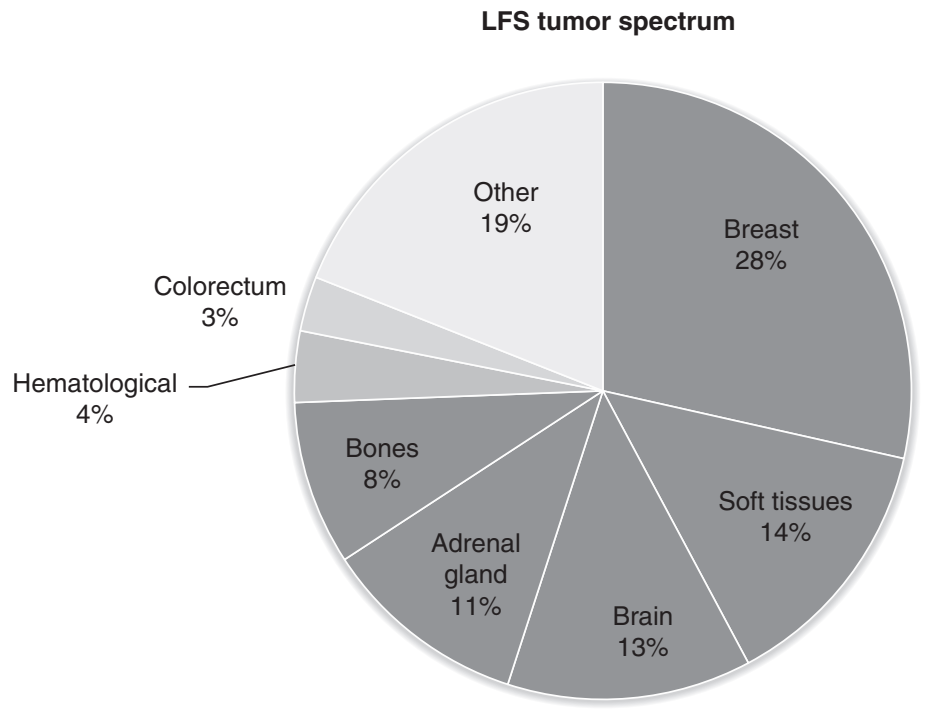

Figure 1. Five core cancers associated with Li-Fraumeni syndrome (LFS). 
analysis of 494 tumors from patients with confirmed or obligate TP53 mutation status and a family history of cancer reported a bias in males for brain tumors, hematopoetic, and stomach cancers. Conversely, an excess of females were reported with a diagnosis of ACC and skin cancer. Both genders were equally affected by soft-tissue and bone sarcomas. This gender distribution of tumors is similar to that seen in sporadic cancers, with the exception of ACC (Olivier et al. 2003). The age of onset of tumors in LFS patients is accelerated compared with their respective sporadic counterparts. The age distribution within "core" LFS cancer types, however, reflects somewhat of a bimodal distribution with brain tumors, soft tissue sarcomas, and ACC commonly occurring within the first decade of life, whereas bone sarcomas predominate during the second decade. Breast cancer is most commonly premenopausal (Olivier et al. 2003).

\section{STRONG TUMOR ASSOCIATIONS WITH GERMLINE TP53 MUTATIONS}

Although germline TP53 mutation carriers can present with tumors of several other organs as briefly noted above, the underlying etiology of the specificity of the "core" tissue types associated with the syndrome remains to be understood. The two exceptions in terms of infrequent diagnosis, yet strong correlation with LFS, are ACC and CPC. ACCs account for only $6.5 \%$ of LFS tumors, yet the prevalence of a germline TP53 mutation in ACC patients is 50\% (Wasserman et al. 2015). However, this strong association between tumor type and germline TP53 mutation is seen almost exclusively in ACC patients diagnosed during childhood (the incidence of germline mutations decreases to $25 \%$ in ACC patients diagnosed $>12$ years of age and has been only rarely reported in adult onset ACC (Wasserman et al. 2015). These findings provide the basis for current recommendations of all ACC patients being offered TP53 testing, regardless of family history.

Similarly, CPCs are exceedingly rare tumors (accounting for a fraction of $1 \%$ of childhood brain tumors), yet are highly associated with germline TP53 mutations. Following several case reports of mutation positive LFS families and individuals diagnosed with CPCs, yet without a family history of cancer (Garber et al. 1990; Yuasa et al. 1993; Vital et al. 1998; Wang and Cornford 2002; Krutilkova et al. 2005), revisions were made to the Chompret criteria to include TP53 testing for all CPC and ACC patients (Tinat et al. 2009). In a study by Gonzalez et al. (2009), all nine patients diagnosed with choroid plexus tumors (CPT) in the study population were found to have germline TP53 mutations (only three of seven patients with sufficient clinical history were found to meet classic Chompret criteria alone). In another retrospective study of 42 patients diagnosed with CPT, six patients $(14.3 \%)$ were found to meet clinical criteria of LFS, with four of the six patients testing positive for germline TP53 mutations (Gozali et al. 2012). Further profiling of CPC patients harboring germline TP53 mutations using high-resolution single-nucleotide polymorphism (SNP) array analysis has led to stratification recommendations within LFS patients diagnosed with this tumor. CPC patients with low total structural variation and absence of $\mathrm{p} 53$ dysfunction in tumors were found to respond better to radiation therapy for a more favorable prognosis (Tabori et al. 2010). Thus, an understanding of the genetic basis of a particular patient's tumor from the germline may be of importance to selection of treatment options.

In another study by Magnusson et al. (2012), the frequency of germline TP53 mutations and family history was studied in patients diagnosed with ACC, CPC, or RMS ( $n=36$ for pedigree screening, and $n=26$ for mutation screening). Although none of the patients met classic LFS criteria, 50\% with ACC, and one of 18 patients with RMS harbored germline TP53 mutations, suggesting that few seemingly "sporadic" cases predispose individuals to early manifestations of LFS.

\section{RISK OF MULTIPLE PRIMARY TUMORS AND SECONDARY CANCERS}

Because of the inherent nature of the syndrome, LFS patients are at an increased risk 
Inherited TP53 Mutations and Li-Fraumeni Syndrome

of developing multiple primary tumors (nontherapy induced) (Gonzalez et al. 2009). In a study of 24 LFS families diagnosed between 1968 and 1986, Hisada et al. (1998) quantified the incidence of second and third primary cancers. Among 200 family members diagnosed with cancer, $15 \%, 4 \%$, and $2 \%$ of individuals developed a second, third, or fourth cancer, respectively. A positive relationship was found between relative risk of developing a second cancer and the onset of the first cancer at an early age. Interestingly, $71 \%$ of the multiple cancers developed were LFS component tumors (Hisada et al. 1998). Although it has been posited that therapy, radiation, or chemotherapy for first malignancies may accelerate the development of subsequent tumors (with the biologic basis for such a hypothesis being supported), no empiric data from large population multicenter studies exist as yet to confirm what therapeutic interventions might accelerate tumorigenesis or whether certain tissues are at particularly higher risk.

\section{CANCER RISK PATTERNS- EPIDEMIOLOGICAL ANALYSIS OF LFS}

From a retrospective study of 13 families, the lifetime risk of developing cancer in mutation carriers was estimated to be $\sim 73 \%$ in males, and as high as $93 \%$ in females (onset of breast cancer accounting for the difference in genders) (Table 1) (Chompret et al. 2000).

The spectrum of cancer risk in LFS was further defined in a retrospective analysis of 56 germline TP53 mutation carriers and 3201 noncarriers from 107 kindreds ascertained through patients treated for soft tissue sarcomas at the University of Texas M.D. Anderson Cancer (Hwang et al. 2003). Cancer risk was deter-

Table 1. Lifetime risk of cancer onset in TP53 mutation carriers characterized by age and gender

\begin{tabular}{lcc}
\hline $\begin{array}{l}\text { Age group } \\
\text { (years) }\end{array}$ & $\begin{array}{c}\text { Lifetime risk } \\
\text { (male) }\end{array}$ & $\begin{array}{c}\text { Lifetime risk } \\
\text { (female) }\end{array}$ \\
\hline$<15$ & $19 \%$ & $12 \%$ \\
$16-45$ & $27 \%$ & $82 \%$ \\
$>45$ & $54 \%$ & $100 \%$ \\
\hline
\end{tabular}

mined for mutation carriers and comparable noncarriers followed for $>20$ years. The percentage of mutation carriers found to develop cancer by ages $20,30,40$, and 50 years was found to be $12 \%, 35 \%, 52 \%$, and $80 \%$, respectively, whereas noncarriers had risks similar to the general population. Observed cancer risks were found to be higher in female carriers compared with males, and not found to be attributed to an excess of gender-specific cancers in contrast to the Chompret data. Mutation carriers were also reported to have a 12-fold higher risk in developing a second primary cancer (Hwang et al. 2003). Regardless, the penetrance of the cancer phenotype in this syndrome is remarkably high.

\section{GENOTYPE-PHENOTYPE CORRELATION IN BRAZILIAN FAMILIES WITH A GERMLINE TP53 MUTATION}

To date, the only molecular variant consistently associated with a specific LFS tumor type is a germline TP53 mutation at codon $\mathrm{R} 337 \mathrm{H}$ (c.1010G $>$ A). This variant is particularly prevalent in the Brazilian population, thought to be because of a founder effect (Ribeiro et al. 2001; Figueiredo et al. 2006), and predisposing individuals to ACC (see Achatz and Zambetti 2016). Initially identified in children with ACC in families with no reported cancer history, the variant codes for a mutant p53 that is strikingly dependent on physiological $\mathrm{pH}$ levels. At $\mathrm{pH}$ levels up to 7.5 , the mutant protein retains its wild-type function; however, at high $\mathrm{pH}$, the protein is unable to form dimers in its natural form, hence losing the ability to function as a transcription factor. This dependency on alternative physiological conditions may partially contribute to the incomplete penetrance and heterogeneous tumor patterns seen in Brazilian families harboring the $\mathrm{R} 337 \mathrm{H}$ variant. More recent comprehensive studies in the Brazilian cohort confirms that, although ACC appears to be particularly more prevalent than is associated with other TP53 mutant genotypes, a wide spectrum of cancers, not dissimilar from the those found in classic LFS, do occur. The penetrance of this allele may be lower than others, yet the carrier rate within the Brazilian population is 
very high-estimated to be as much as 1:350, which has led to calls for TP53 to be added to the newborn testing screen in that country.

\section{GENETIC MODIFIERS IN LFS}

The heterogeneous clinical presentation of LFS, including age of onset and tumor subtype, is highly suggestive of the presence of additional genetic modifiers to the preexisting TP53 germline mutation. However, the highly complex regulatory pathway of upstream and downstream effectors of $\mathrm{p} 53$ function, together with the relative rarity of LFS itself, creates challenges for identifying and determining a functional role for such modifiers.

One of the first variants shown to modify the phenotype conferred by germline TP53 mutations was a secondary $72 \mathrm{Arg}$ polymorphism in the fourth exon of TP53. The variant was shown to have an increased affinity toward MDM2, causing higher levels of p53 degradation, and a lower mean age of tumor onset compared with Pro:Pro carriers (Bougeard et al. 2006). The SNP309 $T>G$ variant in the promoter of $M D M 2$, a key negative regulator of TP53, was also shown to lead to a higher affinity for the Sp1 transcription-factor-binding site, consequently leading to higher MDM2 expression levels and higher levels of p53 degradation (Bond et al. 2004). The variant correlated with a lower mean age of tumor onset in LFS patients in comparison to homozygous $\mathrm{T}$ allele carriers (Bond et al. 2004). A further synergistic effect of lower age of onset and cancer risk mediated through MDM2 affinity was found with the coexistence of both MDM2 SNP309 and 72Arg polymorphism (Bougeard et al. 2006). Notably, those LFS patients harboring both genetic modifiers had the lowest mean age of onset (16.9 years), compared with those patients with either one, or no variants noted above. Fang et al. (2010) noted, in carriers of MDM2 SNP309 (GG/GT), that diagnosis of cancer occurred an average of 9 years earlier than TT carriers (18.6 years vs. 27.6 years). The association was notably more pronounced in female carriers. Individuals with the PP genotype at codon 72 of TP53 had a 2.24-fold increased chance of developing cancer $(p=0.03)$. An additive effect of increased risk was seen for carriers of both MDM2 SNP309 and TP53 codon72 (Fang et al. 2010).

Another potential genetic modifier identified in LFS patients is a 16-base-pair duplication of TP53 in intron 3 (PIN3), which in Brazilian patients harboring the $\mathrm{R} 337 \mathrm{H}$ mutation has a significant "protective" effect on age of onset. Those patients carrying one minor allele (16 bp duplication) were found to have a first cancer diagnosis an average of 17.1 years later than individuals carrying two major (nonduplicated) alleles. Further analysis has identified a higher susceptibility to breast and colorectal cancer in duplicated PIN3 allele carriers (Gemignani et al. 2004; Costa et al. 2008), and lymph node metastasis in germline TP53 mutation carriers with breast cancer (Hrstka et al. 2009). A recently described miRNA, miR-605, which has been shown to regulate the p53-MDM2 loop, has also been described as a potential modifier of the LFS phenotype. The variant G allele of $m i R-605$ gene was found to associate with a 10-year accelerated mean age tumor onset in LFS patients, with a subsequent 2.6-fold reduction in the processing levels of its host miRNA. Overexpression of miR-605 in vitro TP53 mutationcarrying cells showed a reduction in oncogenic properties, with evidence of decreased cellular proliferation, clonogenicity, and migration potential. These results suggest that modulation of miR-605 levels may serve as a novel therapeutic target for LFS spectrum tumors (Id Said and Malkin 2014). Although a germline TP53 mutation appears to be necessary for the increased predisposition to cancer observed in LFS, it is not sufficient in defining the precise cancer phenotype in a patient-which is more likely attributable to a complex interplay of clearly many genetic (and likely genomic and epigenetic) comodifiers (many still yet to be discovered).

\section{GENETIC ANTICIPATION AND GENOMIC INSTABILITY OF LFS}

Genetic anticipation has long been observed in LFS, where the inheritance of a germline TP53 mutation is associated with earlier-onset tu- 
mors in successive generations (Brown et al. 2005). Although the molecular basis of anticipation is not well understood, accelerated telomere erosion across generations is thought to be one potential mechanism in LFS. In both children and adults, studies have shown affected LFS patients to harbor shorter telomere lengths measured in peripheral blood leukocytes as compared with unaffected carriers or controls (Tabori et al. 2007; Trkova et al. 2007). Even within a family, affected children were found to have shorter telomere lengths than their unaffected siblings and TP53 wild-type parents (Tabori et al. 2007). Although measuring telomere length may be a rational biological marker for monitoring cancer initiation and progression, it is still considered to be a relatively crude method for detecting early cancer onset in LFS patients.

In addition to telomere shortening, Shlien et al. (2008) identified copy number variation (CNV) to also contribute to increased genomic instability in LFS patients. Using high-resolution SNP/CNV array analysis, a significantly higher number of copy number variable regions were found in the genomes of TP53 carriers compared with the general population. Interestingly, high frequencies of these $\mathrm{CNV}$ regions were found to overlap known cancer genes, and the number of CNVs seemed to increase gradually in somatic cells of LFS tumors, suggestive of a dynamic process of CNV accumulation contributing to genomic instability and tumorigenicity in LFS (Shlien et al. 2008).

\section{MOUSE MODELS OF LI-FRAUMENI SYNDROME}

The first clues of cancer susceptibility attributed to germline TP53 mutations in a mouse model were seen in 1992, using homozygous knockout mice with a germline Trp53 deletion (Donehower et al. 1992). These mice were found to be developmentally normal, yet highly susceptible to T-cell lymphomas and sarcomas (with rare occurrences of carcinomas in C57BL/6 and $129_{4}$ /SvJae backgrounds) by 6 months of age. Interestingly, these tumors were rarely found to metastasize (Donehower et al. 1992). Although molecular mechanisms of functionally null TP53 germline mutations were well outlined from this model, perhaps a closer genetic model of LFS was reflected in the Trp53 mutant heterozygous mice. These mice developed metastatic tumor phenotypes, providing physiological evidence for mutant p53 gain-of-functionspecific phenotypes (Lang et al. 2004; Olive et al. 2004). Interestingly, mice with two different missense mutations in the same genetic background were found to develop different tumor spectra (Olive et al. 2004), resembling to a certain degree what is observed in humans with LFS.

When looking at C57BL6 background mice specifically, the majority of $\operatorname{Tr} p 53^{+/-}$mice were found to develop tumors by 18 months of age, with a higher incidence of bone, soft tissue sarcomas, and carcinomas compared with $\operatorname{Tr} p^{-/-}$ mice (Harvey et al. 1993). It is interesting to note that only $55 \%$ of the tumors examined from heterozygous mice showed loss of heterozygosity of the wild-type allele $(n=33)$, an observation consistent with the human condition as well, with no association to a particular tumor type (Harvey et al. 1993), suggestive of p53 dosage reduction having the potential to initiate cancer growth (Venkatachalam et al. 1998). Although tumor types of the heterozygous C57BL6 $\operatorname{Trp5} 3^{+/-}$mouse model were reminiscent of those seen in LFS, the absence of breast and brain tumors, noted to be important LFS component tumors, rendered the model only partially representative of the human syndrome (Harvey et al. 1993). It was later understood that genetic background played an important role in predisposition of tumor types, as C57BL6 were found to have an intrinsic resistance to mammary carcinomas (Kuperwasser et al. 2000). Interestingly, a backcross of the Trp53null allele into a mammary tumor-susceptible $\mathrm{Balb} / \mathrm{c}$ background resulted in 55\% of the female heterozygous mice to present with a mammary carcinoma, validating the role of the genetic background influencing tumor subtypes arising in Trp53-deficient mice (Kuperwasser et al. 2000).

Although studying p53-null mice helped better elucidate the mechanisms of p53-medi- 
ated tumorigenesis, the functional relevance of the $>80 \%$ of missense mutations characteristic of the human syndrome was still not well understood. This led to the development of knockin mouse models of hotspot mutations, homologous to those found in human germline TP53 mutant carriers. More specifically, the $\operatorname{Tr} p^{R 172 H}$ model in a $129 \mathrm{~S}_{4} /$ Sv background (corresponding to $\mathrm{p} 53^{\mathrm{R} 175 \mathrm{H}}$ mutations in humans) showed a high frequency of metastatic tumors (consistent with the spectrum of tumors in LFS) compared with its rare occurrence in heterozygous mice (Liu et al. 2000). This was suggestive of a gain-of-function effect of TP53. Interestingly, this phenotype persisted despite mutant p53 protein levels being as low as those observed in wild-type mice because of an additional splicing abnormality (Liu et al. 2000). In addition to the development of carcinomas, softtissue and bone sarcomas, leukemias, and especially the onset of glioblastoma multiforme (the most common brain tumor in LFS patients) was promising to mimic the human syndrome. Backcrossing to a BALB/C background notably resulted in the heterozygous mice to develop mammary carcinomas, further refining the accuracy of this particular knockin model (Xiong et al. 2014).

Another knockin model, encompassing the $\operatorname{Tr} p^{R 270 H}$ missense mutation (corresponding to the $\mathrm{p} 53^{\mathrm{R} 273 \mathrm{H}}$ mutation in humans) in a 129S4/ Sv background, was found to develop an increased tumor burden, particularly of carcinomas and B-cell lymphomas, and increased metastatic potential compared with heterozygous knockout models. The difference in tumor spectra between the $\operatorname{Tr} p^{R 172 H}$ and $\operatorname{Tr} p^{R 270 H}$ models can partially be explained by the $\operatorname{Tr} p^{R 172 H}$ representing a conformational mutant, whereas the $\operatorname{Trp}{ }^{R 270 H}$ representing a contact mutant (Olive et al. 2004). Although it is compelling to hypothesize that different germline TP53 mutations in LFS patients give rise to different tumor types, further genotype-phenotype studies in mice remain to be conducted for further validation.

A knockin model of a rare TP53 mutation, a R175P amino acid change switch, has also led to some intriguing results. This particular mutation has yet to be identified in LFS; however, it is commonly found in sporadic cancers. Cells from $\operatorname{Tr} p^{515} \mathrm{C} / 515 \mathrm{C}$ mice (coding for a R172P switch in $\operatorname{Trp} 53$ in mice) were shown to behave similar to p53-null cells, unable to initiate apoptosis. However, functional studies have shown its ability to still induce cell-cycle arrest and maintain a stable genome. Most interestingly, $\operatorname{Tr} p^{515 C / 515 C}$ mice were found to have a delayed tumor onset compared with homozygous mutant mice, suggesting delayed cell-cycle arrest to contribute to tumor suppression (Liu et al. 2004). The observation of diverse tumor spectra and neoplastic tendencies in different germline Trp53 mutations and background strains, further validates the complexity of p53-mediated cancer predisposition. Regardless, mouse models have further elucidated molecular and pathogenic mechanisms of tumorigenicity in LFS.

\section{SURVEILLANCE PROTOCOL FOR LFS}

Because of the high-lifetime risk of neoplasms in LFS, periodic surveillance of clinically asymptomatic LFS patients is crucial for detection of occult cancer, potentially offering a better prognosis. The establishment of a structured, comprehensive surveillance protocol by Villani et al. (2011), combining noninvasive biochemical and imaging modalities for early detection of asymptomatic tumors in germline TP53 mutation carriers, showed potential for efficacious management of disease and a survival advantage of followed patients. Of the 18/33 germline TP53 mutation carriers undergoing surveillance in the study, 10 asymptomatic tumors were identified in seven patients. Detected tumors included small, localized high-grade tumors, such as choroid plexus carcinomas, as well as low-grade and premalignant lesions (having potential to progress to a more malignant state). The following protocol developed at the Hospital for Sick Children in Toronto in 2011 has been implemented or adapted by numerous institutions worldwide (Table 2).

Implementation of a surveillance protocol not only confers survival advantage for LFS patients, but also provides further credibility for 
Inherited TP53 Mutations and Li-Fraumeni Syndrome

Table 2. Clinical surveillance protocol for asymptomatic germline TP53 mutation carriers

\begin{tabular}{|c|c|c|}
\hline Cohort & Tumor type & Criteria \\
\hline \multirow[t]{4}{*}{ Children } & $\begin{array}{l}\text { Adrenocortical } \\
\text { carcinoma }\end{array}$ & $\begin{array}{l}\text { Ultrasound of abdomen and pelvis every } 3 \text { to } 4 \text { months } \\
\text { Complete urinalysis every } 3 \text { to } 4 \text { months } \\
\text { Blood tests every } 4 \text { months: } \beta \text {-human chorionic gonadotropin, } \\
\alpha \text {-fetoprotein, } 17-\mathrm{OH} \text {-progesterone, testosterone, } \\
\text { dehydroepiandrosterone sulfate, androstenedione }\end{array}$ \\
\hline & Brain tumor & Annual brain MRI \\
\hline & $\begin{array}{l}\text { Soft-tissue and brain } \\
\text { sarcoma }\end{array}$ & Annual rapid total body MRI \\
\hline & Leukemia/lymphoma & $\begin{array}{l}\text { Blood test every } 4 \text { months: complete blood count, erythrocyte } \\
\text { sedimentation rate, lactate dehydrogenase }\end{array}$ \\
\hline \multirow[t]{6}{*}{ Adult } & Breast cancer & $\begin{array}{l}\text { Monthly breast self-examination starting at age } 18 \text { years } \\
\text { Clinical breast examination twice a year, starting at age } 20-25 \text { years, } \\
\text { or } 5-10 \text { years before the earliest known breast cancer in the family } \\
\text { Annual mammography and breast MRI screening starting at age } \\
20-25 \text { years, or at earliest age of onset in the family } \\
\text { Consider risk-reducing bilateral mastectomy }\end{array}$ \\
\hline & Brain tumor & Annual brain MRI \\
\hline & $\begin{array}{l}\text { Soft tissue and bone } \\
\text { sarcoma }\end{array}$ & $\begin{array}{l}\text { Annual rapid total body MRI } \\
\text { Ultrasound of abdomen and pelvis every } 6 \text { months }\end{array}$ \\
\hline & Colon cancer & $\begin{array}{l}\text { Colonoscopy every } 2 \text { years, beginning at age } 25 \text { years, or } 10 \text { years before } \\
\text { the earliest known colon cancer in the family }\end{array}$ \\
\hline & Melanoma & Annual dermatological examination \\
\hline & Leukemia/lymphoma & $\begin{array}{l}\text { Complete blood count every } 4 \text { months } \\
\text { Erythrocyte sedimentation rate, lactate dehydrogenase every } \\
4 \text { months }\end{array}$ \\
\hline
\end{tabular}

Data modified from Villani et al. (2011).

the importance of early genetic testing. At the time of writing, the long-term benefits of the large-scale surveillance strategies in reducing tumor burden and improving patient survival are being further evaluated. Reported psychological benefits, specifically a sense of control and sensitivity, can potentially be associated with implementation of such a surveillance protocol (Lammens et al. 2010).

\section{GENETIC COUNSELING AND TESTING FOR LFS FAMILY MEMBERS}

Because of the strikingly increased probability of cancer onset in LFS families, periodic genetic counseling is offered to high-risk family members, with the goal of better management of disease. Because of limited preventative options available for LFS patients however (with the exception of prophylactic mastectomy to reduce the risk of breast cancer in females), there still remains a debate on the medical benefits of genetic screening, specifically addressing the adverse psychological effects that may come along with counseling (Committee on Bioethics 2001; Robson et al. 2015). It should be recognized, however, that LFS families can potentially benefit from genetic counseling, by obtaining a sense of control, and to some extent, certainty regarding one's own risks, and that of their offspring (Claes et al. 2004). Positive tests can be informative for extended family members, for future family planning, and in regard to assessing their risk. Conclusive negative tests can lead to further avoidance of unnecessary medical interventions.

As one can imagine, the notion of undergoing routine surveillance and early genetic testing for LFS patients comes along with other psychosocial risks, which have only briefly been looked at previously. LFS family members may be repeatedly exposed to cancer diagnoses, 
either for themselves, or affected family members. A higher chance of death can also lead to considerable psychological impact. Understandably, the decision of undergoing genetic testing for at-risk individuals may lead to an internal conflict of the possibility of being a carrier, and the consequences of this knowledge for themselves and their family members. It is therefore important to address the psychological distress experienced by LFS patients and their families, as it may impact their decisions for genetic testing and follow-up care.

\section{REFERENCES}

${ }^{*}$ Reference is also in this collection.

* Achatz MI, Zambetti GP. 2016. The inherited p53 mutation in the Brazilian population. Cold Spring Harb Perspect Med doi: 10.1101/cshperspect.a026195.

Birch JM, Hartley AL, Tricker KJ, Prosser J, Condie A, Kelsey AM, Harris M, Jones PH, Binchy A, Crowther D, et al. 1994. Prevalence and diversity of constitutional mutations in the $p 53$ gene among $21 \mathrm{Li}-$ Fraumeni families. Cancer Res 54: 1298-1304.

Bond GL, Hu W, Bond EE, Robins H, Lutzker SG, Arva NC, Bargonetti J, Bartel F, Taubert H, Wuerl P, et al. 2004 A single nucleotide polymorphism in the MDM2 promoter attenuates the 553 tumor suppressor pathway and accelerates tumor formation in humans. Cell 119: $591-$ 602.

Bougeard G, Baert-Desurmont S, Tournier I, Vasseur S, Martin C, Brugieres L, Chompret A, Bressac-de Paillerets B, Stoppa-Lyonnet D, Bonaiti-Pellie C, et al. 2006. Impact of the MDM2 SNP309 and p53 Arg72Pro polymorphism on age of tumour onset in $\mathrm{Li}-$ Fraumeni syndrome. J Med Genet 43: 531-533.

Brown BW, Costello TJ, Hwang SJ, Strong LC. 2005. Generation or birth cohort effect on cancer risk in Li-Fraumeni syndrome. Hum Genet 118: 489-498.

Chompret A, Brugières L, Ronsin M, Gardes M, DessarpsFreichey F, Abel A, Hua D, Ligot L, Dondon MG, Bressacde Paillerets B, et al. 2000. P53 germline mutations in childhood cancers and cancer risk for carrier individuals. Br J Cancer 82: 1932-1937.

Chompret A, Abel A, Stoppa-Lyonnet D, Brugiéres L, Pagés S, Feunteun J, Bonaïti-Pellié C. 2001. Sensitivity and predictive value of criteria for $p 53$ germline mutation screening. J Med Genet 38: 43-47.

Claes E, Denayer L, Evers-Kiebooms G, Boogaerts A, Legius E. 2004. Predictive testing for hereditary non-polyposis colorectal cancer: Motivation, illness representations and short-term psychological impact. Patient Educ Couns 55: 265-274.

* Comeaux EQ, Mullighan CG. 2016. TP53 mutations in hypodiploid acute lymphoblastaic leukemia. Cold Spring Harb Perspect Med doi: 10.1101/cshperspect.a026286.
Committee on Bioethics. 2001. Ethical issues with genetic testing in pediatrics. Pediatrics 107: 1451-1455.

Costa S, Pinto D, Pereira D, Rodrigues H, Cameselle-Teijeiro J, Medeiros R, Schmitt F. 2008. Importance of TP53 codon 72 and intron 3 duplication 16bp polymorphisms in prediction of susceptibility on breast cancer. BMC Cancer 8: 32 .

Donehower LA, Harvey M, Slagle BL, McArthur MJ, Montgomery CA Jr, Butel JS, Bradley A. 1992. Mice deficient for p53 are developmentally normal but susceptible to spontaneous tumours. Nature 356: 215-221.

Eeles RA. 1995. Germline mutations in the TP53 gene. Cancer Surv 25: 101-124.

Fang S, Krahe R, Lozano G, Han Y, Post SM, Zhang B, Wilson CD, Bachinski LL, Strong LC, et al. 2010. Effects of MDM2, MDM4 and TP53 codon 72 polymorphisms on cancer risk in a cohort study of carriers of TP53 germline mutations. PLoS ONE 5: e10813.

Figueiredo BC, Sandrini R, Zambetti GP, Pereira RM, Cheng C, Liu W, Lacerda L, Pianovski MA, Michalkiewicz E, Jenkins J, et al. 2006. Penetrance of adrenocortical tumours associated with the germline TP53 R337H mutation. J Med Genet 43: 91-96.

Garber JE, Burke EM, Lavally BL, Billett AL, Sallan SE, Scott RM, Kupsky W, Li FP. 1990. Choroid plexus tumors in the breast cancer-sarcoma syndrome. Cancer 66: 2658-2660.

Gemignani F, Moreno V, Landi S, Moullan N, Chabrier A, Gutiérrez-Enríquez S, Hall J, Guino E, Peinado MA, Capella G, et al. 2004. A TP53 polymorphism is associated with increased risk of colorectal cancer and with reduced levels of TP53 mRNA. Oncogene 23: 1954-1956.

Gonzalez KD, Noltner KA, Buzin CH, Gu D, Wen-Fong CY, Nguyen VQ, Han JH, Lowstuter K, Longmate J, Sommer SS, et al. 2009. Beyond Li-Fraumeni syndrome: Clinical characteristics of families with $p 53$ germline mutations. J Clin Oncol 27: 1250-1256.

Gozali AE, Britt B, Shane L, Gonzalez I, Gilles F, McComb JG, Krieger MD, Lavey RS, Shlien A, Villablanca JG, et al. 2012. Choroid plexus tumors; management, outcome, and association with the $\mathrm{Li}-$ Fraumeni syndrome: The Children's Hospital Los Angeles (CHLA) Experience, 1991-2010. Pediatr Blood Cancer 58: 905-909.

Harvey M, McArthur MJ, Montgomery CA Jr, Butel JS, Bradley A, Donehower LA. 1993. Spontaneous and carcinogen-induced tumorigenesis in p53-deficient mice. Nat Genet 5: 225-229.

Hettmer S, Archer N, Somers G, Novokmet A, Wagers A, Diller L, Rodriguez-Galindo C, Teot L, Malkin D. 2014. Anaplastic rhabdomyosarcoma in TP53 germline mutation carriers. Cancer 120: 1068-1075.

Hisada M, Garber JE, Fung CY, Fraumeni JF Jr, Li FP. 1998 Multiple primary cancers in families with Li-Fraumeni syndrome. J Natl Cancer Inst 90: 606-611.

Hrstka R, Beranek M, Klocova K, Nenutil R, Vojtesek B. 2009. Intronic polymorphisms in TP53 indicate lymph node metastasis in breast cancer. Oncol Rep 22: 12051211.

Hwang SJ, Lozano G, Amos CI, Strong LC. 2003. Germline p53 mutations in a cohort with childhood sarcoma: Sex differences in cancer risk. Am J Hum Genet 72: 975-983. 
Id Said B, Malkin D. 2014. A functional variant in miR-605 modifies the age of onset in $\mathrm{Li}-\mathrm{Fraumeni}$ syndrome. Cancer Genet 208: 47-51.

Krutilkova V, Trkova M, Fleitz J, Gregor V, Novotna K, Krepelova A, Sumerauer D, Kodet R, Siruckova S, Plevova P, et al. 2005. Identification of five new families strengthens the link between childhood choroid plexus carcinoma and germline TP53 mutations. Eur J Cancer 41: $1597-$ 1603.

Kuperwasser C, Hurlbut GD, Kittrell FS, Dickinson ES, Laucirica R, Medina D, Naber SP, Jerry DJ. 2000. Development of spontaneous mammary tumors in BALB/c p53 heterozygous mice. A model for $\mathrm{Li}-\mathrm{Fraumeni}$ syndrome. Am J Pathol 157: 2151-2159.

Lammens CR, Bleiker EM, Aaronson NK, Wagner A, Sijmons RH, Ausems MG, Vriends AH, Ruijs MW, van Os TA, Spruijt L, et al. 2010. Regular surveillance for Li-Fraumeni syndrome: Advice, adherence and perceived benefits. Fam Cancer 9: 647-654

Lang GA, Iwakuma T, Suh YA, Liu G, Rao VA, Parant JM, Valentin-Vega YA, Terzian T, Caldwell LC, Strong LC, et al. 2004. Gain of function of a p53 hot spot mutation in a mouse model of Li-Fraumeni syndrome. Cell 119: 861872.

Li FP, Fraumeni JF Jr. 1969. Soft-tissue sarcomas, breast cancer, and other neoplasms. A familial syndrome? Ann Intern Med 71: 747-752.

Li FP, Fraumeni JF Jr, Mulvihill JJ, Blattner WA, Dreyfus MG, Tucker MA, Miller RW. 1988. A cancer family syndrome in twenty-four kindreds. Cancer Res 48: 53585362.

Liu G, McDonnell TJ, Montes de Oca Luna R, Kapoor M, Mims B, El-Naggar AK, Lozano G. 2000. High metastatic potential in mice inheriting a targeted p53 missense mutation. Proc Natl Acad Sci 97: 4174-4179.

Liu G, Parant JM, Lang G, Chau P, Chavez-Reyes A, El-Naggar AK, Multani A, Chang S, Lozano G. 2004. Chromosome stability, in the absence of apoptosis, is critical for suppression of tumorigenesis in Trp53 mutant mice. Nat Genet 36: 63-68.

Lynch HT, Mulcahy GM, Harris RE, Guirgis HA, Lynch JF. 1978. Genetic and pathologic findings in a kindred with hereditary sarcoma, breast cancer, brain tumors, leukemia, lung, laryngeal, and adrenal cortical carcinoma. Cancer 41: 2055-2064.

Magnusson S, Gisselsson D, Wiebe T, Kristoffersson U, Borg A, Olsson H. 2012. Prevalence of germline TP53 mutations and history of $\mathrm{Li}$-Fraumeni syndrome in families with childhood adrenocortical tumors, choroid plexus tumors, and rhabdomyosarcoma: A populationbased survey. Pediatr Blood Cancer 59: 846-853.

Mai PL, Malkin D, Garber JE, Schiffman JD, Weitzel JN, Strong LC, Wyss O, Locke L, Means V, Achatz MI, et al. 2012. Li-Fraumeni syndrome: Report of a clinical research workshop and creation of a research consortium. Cancer Genet 205: 479-487.

Malkin D, Li FP, Strong LC, Fraumeni JF Jr, Nelson CE, Kim DH, Kassel J, Gryka MA, Bischoff FZ, Tainsky MA, et al. 1990. Germ line $p 53$ mutations in a familial syndrome of breast cancer, sarcomas, and other neoplasms. Science 250: $1233-1238$.
McCuaig JM, Armel SR, Novokmet A, Ginsburg OM, Demsky R, Narod SA, Malkin D. 2012. Routine TP53 testing for breast cancer under age 30: Ready for prime time? Fam Cancer 11: 607-613.

Nichols KE, Malkin D, Garber JE, Fraumeni JF Jr, Li FP 2001. Germ-line p53 mutations predispose to a wide spectrum of early-onset cancers. Cancer Epidemiol Biomarkers Prev 10: 83-87.

Olive KP, Tuveson DA, Ruhe ZC, Yin B, Willis NA, Bronson RT, Crowley D, Jacks T. 2004. Mutant p53 gain of function in two mouse models of $\mathrm{Li}-\mathrm{Fraumeni}$ syndrome. Cell 119: 847-860.

Olivier M, Goldgar DE, Sodha N, Ohgaki H, Kleihues P, Hainaut P, Eeles RA. 2003. Li-Fraumeni and related syndromes: Correlation between tumor type, family structure, and TP53 genotype. Cancer Res 63: 6643-6650.

Ribeiro RC, Sandrini F, Figueiredo B, Zambetti GP, Michalkiewicz E, Lafferty AR, DeLacerda L, Rabin M, Cadwell C, Sampaio G, et al. 2001. An inherited p53 mutation that contributes in a tissue-specific manner to pediatric adrenal cortical carcinoma. Proc Natl Acad Sci 98: 9330-9335.

Robson ME, Bradbury AR, Arun B, Domchek SM, Ford JM, Hampel HL, Lipkin SM, Syngal S, Wollins DS, Lindor NM. 2015. American Society of Clinical Oncology policy statement update: Genetic and genomic testing for cancer susceptibility. J Clin Oncol 28: 893-901.

Shlien A, Tabori U, Marshall CR, Pienkowska M, Feuk L, Novokmet A, Nanda S, Druker H, Scherer SW, Malkin D. 2008. Excessive genomic DNA copy number variation in the Li-Fraumeni cancer predisposition syndrome. Proc Natl Acad Sci 105: 11264-11269.

Tabori U, Nanda S, Druker H, Lees J, Malkin D. 2007. Younger age of cancer initiation is associated with shorter telomere length in $\mathrm{Li}$-Fraumeni syndrome. Cancer Res 67: 1415-1418.

Tabori U, Shlien A, Baskin B, Levitt S, Ray P, Alon N, Hawkins C, Bouffet E, Pienkowska M, Lafay-Cousin L, et al. 2010. TP53 alterations determine clinical subgroups and survival of patients with choroid plexus tumors. J Clin Oncol 28: 1995-2001.

Tinat J, Bougeard G, Baert-Desurmont S, Vasseur S, Martin C, Bouvignies E, Caron O, Bressac-de Paillerets B, Berthet P, Dugast C, et al. 2009. 2009 version of the Chompret criteria for Li-Fraumeni syndrome. J Clin Oncol 27: $108-109$.

Trkova M, Prochazkova K, Krutilkova V, Sumerauer D, Sedlacek Z. 2007. Telomere length in peripheral blood cells of germline TP53 mutation carriers is shorter than that of normal individuals of corresponding age. Cancer 110: 694-702.

Venkatachalam S, Shi YP, Jones SN, Vogel H, Bradley A, Pinkel D, Donehower LA. 1998. Retention of wild-type p53 in tumors from p53 heterozygous mice: Reduction of p53 dosage can promote cancer formation. EMBO J 17: 4657-4667.

Villani A, Tabori U, Schiffman J, Shlien A, Beyene J, Druker H, Novokmet A, Finlay J, Malkin D. 2011. Biochemical and imaging surveillance in germline TP53 mutation carriers with Li-Fraumeni Syndrome: A prospective observational study. Lancet Oncol 12: 559-567. 
T. Guha and D. Malkin

Vital A, Bringuier PP, Huang H, San Galli F, Rivel J, Ansoborlo S, Cazauran JM, Taillandier L, Kleihues P, Ohgaki H. 1998. Astrocytomas and choroid plexus tumors in two families with identical $p 53$ germline mutations. J Neuropathol Exp Neurol 57: 1061-1069.

Wang L, Cornford ME. 2002. Coincident choroid plexus carcinoma and adrenocortical carcinoma with elevated p53 expression: A case report of an 18-month-old boy with no family history of cancer. Arch Pathol Lab Med 126: $70-72$.

Wasserman JD, Novokmet A, Eichler-Jonsson C, Ribeiro RC, Rodriguez-Galindo C, Zambetti GP, Malkin D.
2015. Prevalence and functional consequence of TP53 mutations in pediatric adrenocortical carcinoma: A children's oncology group study. J Clin Oncol 33: 602609.

Xiong S, Tu H, Kollareddy M, Pant V, Li Q, Zhang Y, Jackson JG, Suh YA, Elizondo-Fraire AC, Yang P, et al. 2014. Pla2g16 phospholipase mediates gain-of-function activities of mutant p53. Proc Natl Acad Sci 111: 1114511150.

Yuasa H, Tokito S, Tokunaga M. 1993. Primary carcinoma of the choroid plexus in Li-Fraumeni syndrome: Case report. Neurosurgery 32: 131-133; discussion 133-134. 


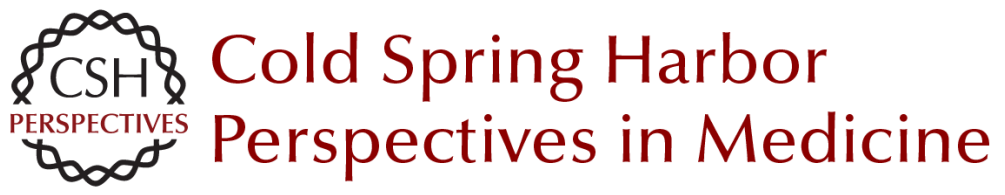

\section{Inherited TP53 Mutations and the Li -Fraumeni Syndrome}

Tanya Guha and David Malkin

Cold Spring Harb Perspect Med 2017; doi: 10.1101/cshperspect.a026187 originally published online March 7, 2017

\section{Subject Collection The p53 Protein}

Targeting the MDM2-p53 Protein-Protein Interaction for New Cancer Therapy: Progress and Challenges

Shaomeng Wang, Yujun Zhao, Angelo Aguilar, et al.

Structural Evolution and Dynamics of the p53

Proteins

Giovanni Chillemi, Sebastian Kehrloesser,

Francesca Bernassola, et al.

Exploiting the p53 Pathway for Therapy Chit Fang Cheok and David Philip Lane

The Regulation of Cellular Functions by the p53 Protein: Cellular Senescence Crystal A. Tonnessen-Murray, Guillermina Lozano and James G. Jackson

The Transactivation Domains of the p53 Protein Nitin Raj and Laura D. Attardi

The Evolution of the Ribosomal Protein-MDM2p53 Pathway

Chad Deisenroth, Derek A. Franklin and Yanping Zhang

Somatic TP53 Mutations in the Era of Genome

Sequencing

Pierre Hainaut and Gerd P. Pfeifer

The Paradox of p53: What, How, and Why? Yael Aylon and Moshe Oren
Control of Cellular Aging, Tissue Function, and Cancer by p53 Downstream of Telomeres Caitlin M. Roake and Steven E. Artandi

Inherited TP53 Mutations and the Li -Fraumeni Syndrome

Tanya Guha and David Malkin

TP53 Mutations in Hypodiploid Acute Lymphoblastic Leukemia

Evan Q. Comeaux and Charles G. Mullighan

Transcriptional Regulation by Wild-Type and

Cancer-Related Mutant Forms of p53

Neil T. Pfister and Carol Prives

The Inherited p53 Mutation in the Brazilian Population

Maria Isabel Achatz and Gerard P. Zambetti

TP53 Mutations in Breast and Ovarian Cancer Laxmi Silwal-Pandit, Anita Langerød and Anne-Lise Børresen-Dale

p53 and the Carcinogenicity of Chronic Inflammation

Andrei V. Gudkov and Elena A. Komarova

Oncogenic Mutant p53 Gain of Function

Nourishes the Vicious Cycle of Tumor

Development and Cancer Stem-Cell Formation

Yoav Shetzer, Alina Molchadsky and Varda Rotter

For additional articles in this collection, see http://perspectivesinmedicine.cshlp.org/cgi/collection/ 